\title{
Ultrasound-assisted extraction and gaseous ozone as preservation method for Roselle (Hibiscus sabdariffa L.) fruit juice
}

\author{
${ }^{1,2 *}$ Shah, N.N.A.K., ${ }^{1}$ Ong, M.C., ${ }^{1}$ Supian, N.M.A. and ${ }^{1}$ Sulaiman, A. \\ ${ }^{1}$ Department of Process and Food Engineering, Faculty of Engineering, Universiti Putra Malaysia, 43400, \\ UPM Serdang, Selangor, Malaysia. \\ ${ }^{2}$ Halal Products Research Institute, Putra Infoport, Universiti Putra Malaysia. 43400 Serdang, Malaysia.
}

\begin{abstract}
Article history:
Received: 14 April 2020

Received in revised form: 17

July 2020

Accepted: 19 September 2020

Available Online: 27

December 2020
\end{abstract}

Keywords:

Ultrasound,

Ozone,

Fruit juice,

Roselle,

Physicochemical,

Antioxidant properties

DOI:

https://doi.org/10.26656/fr.2017.4(S6).024

\begin{abstract}
Ultrasound extraction and ozone treatment are promising non-thermal hurdle technologies which can increase the extraction yield while minimizing the loss of nutritional qualities of Roselle fruit juice. Response surface methodology (RSM) was used to investigate the effect of ultrasound time and temperature on juice yield. The optimized points were found at $4.4 \mathrm{~min}$ and $22^{\circ} \mathrm{C}$, where the extraction yield of the Roselle fruit juice achieved a maximum of $80 \%, 12 \%$ higher than the control sample without ultrasound treatment. Roselle fruit juice (unfiltered and filtered) was then ozone-treated with processing variable of treatment time (0-30 mins). The effects of processing variables on physicochemical characteristics of Roselle fruit juice were determined and no significant differences $(\mathrm{P}>0.05)$ in $\mathrm{pH}$ and titratable acidity (TA) were observed. However, significant effect $(\mathrm{P}<0.05)$ was found in total colour difference (TCD), ascorbic acid (AA), total phenolic content (TPC), and total anthocyanin content (TAC) with increased ozone treatment time. Nevertheless, the degradation of AA was less than $50 \%$, which showed that ozone has the potential to retain a high amount of AA in Roselle fruit juice. Thus, the synergistic effects of ultrasound and ozone treatment on Roselle fruit juice should be carefully considered by processors prior to its adoption as a preservation technique.
\end{abstract}

\section{Introduction}

Roselle (Hibiscus sabdariffa L.) is a tropical wild plant belonging to the Malvaceae family and it is widely grown in Central and West Africa and South-East Asia (Ansari et al., 2013). Roselle is an ideal crop for developing countries as it is relatively easy to grow, can be grown as part of multi-cropping systems and can be used as a source of food and fibre (Da-Costa-Rocha et al., 2014). In Malaysia, Roselle is a fairly new crop to form an industry. In 2017, a total of 54 hectares were planted with three varieties of Roselle; Red Roselle, Wild Red Roselle, and Yellow Roselle. Between 2013 and 2017 about 100 hectares are planted growing 509.5 metric tons of red Roselle calyxes valued at RM 1.1 million (DOA, 2017).

The most exploited part of a Roselle plant is its calyxes. Fleshy calyxes are conventionally used fresh to make wine, jelly, syrup, gelatin, and cakes. While dried calyces are used for tea, marmalade, ice cream, sauces, and other desserts (Ismail et al., 2008). Fresh and dried calyxes have also known to be processed into juices. The presence of anthocyanin and protogutetic compounds in Roselle calyxes makes it a good colourant and a good source of antioxidant components (Naimah et al., 2014). Vitamin C concentrations were reported to be $2.5,3$, and 9 times higher than blackcurrant, grapes, and citrus, respectively (Naimah et al., 2014). In addition to contributing to the colour of the calyxes, anthocyanin, flavonoids, phenolic acids, and other organic acids were reported to minimize various chronic diseases such as cancers, cardiovascular diseases, asthma, and type II diabetes (Pozos et al., 2020). Owing to its high health benefits, Department of Agriculture (DOA), Ministry of Agriculture, Malaysia has urged its farmers to diversify its by-products. Roselle fruit juice has since been making its introduction to the local consumer. However, due to its short shelf-life, most producers sold Roselle juice in concentrated form with added sugar, which is hardly the healthier choice. Hence, this study aims to produce ozone-pasteurized fresh Roselle juice with retained nutritional qualities.

Traditionally, fruit juices are preserved by thermal pasteurization, where they are subjected to a very high 
temperature for a short time (HTST) in order to kill pertinent microorganisms and prolong its shelf-life. However, undesirable changes were observed during the high-energy treatments, such as the change in food flavours, loss of vitamins, essential nutrients, and freshness in the product affects the consumer preferences and demands. As global consumers are becoming more conscious about the need for fresh and healthy juice, the development of novel and inventive technologies arises. To meet these demands, ultrasonication and ozonation, which are non-thermal technologies were proposed for this study. Non-thermal processes produce minimally processed food without the use of heat or keep the processing temperature lower than $45^{\circ} \mathrm{C}$ (Bevilacqua et al., 2018) than thermal pasteurization $\left(60^{\circ} \mathrm{C}\right.$ to $\left.100^{\circ} \mathrm{C}\right)$ (Agcam et al., 2018) in order to retain the natural organoleptic characteristics of fresh juice during and after processing.

The use of ultrasound energy in solid and liquid media has been extensive in food-processing applications and preservation. Ultrasound-assisted extraction (UAE) can be used as a procedure for the preparation and extraction of analytes. The principle of UAE is mainly related to the formation of acoustic cavitation. When ultrasound propagates through any medium, it induces a series of compressions and rarefactions (expansion) in the molecules of the medium (Tiwari, 2015). Thus, the high pressure occurs during the implosion of cavitation micro-bubbles that will destroy the cell wall of the plant matrix which could increase the phenolic and antioxidant content of treated food. Furthermore, the application of ultrasound-assisted extraction (UAE) could improve the extraction yield and reduces processing time. In a study by Gonzalez-Centeno et al. (2015), it was observed that a $2.3-3.0$ fold increase in total phenolic content from grape pomace for $2.5 \mathrm{mins}$ for UAE compared to conventional mechanical agitation. In juice processing, water-soluble components in the fruit flesh must be completely recovered to increase the extraction yield. Nguyen and Le (2012) proved that sonication of pineapple mash in juice processing increased the extraction yield by $10.8 \%$ in comparison with the control sample without ultrasonic treatment. Nevertheless, the cavitation process can be influenced by different parameters, including medium properties, operating frequency, wavelength, ultrasonic intensity, and ambient conditions such as temperature and pressure (Ashokkumar, 2015; Tiwari, 2015; Ali and Maryam, 2016; Chemat et al., 2017). Until the moment of writing, there are limited studies on the application of sonication to increase the extraction yield of Roselle fruit juice. Pozos et al. (2020), Aryanti et al. (2019) and Almahy et al. (2017) have studied the effect of UAE on Roselle calyxes with various parameters (Temp: $25-32^{\circ} \mathrm{C}$,
Time: 20 - 120 mins, Freq: $40 \mathrm{kHz}$, Power: NA). However, all three studies have employed ethanol as a solvent to aid in the extraction of Roselle juice from its calyxes. With the aim of consumers' direct usage, it was deemed unsuitable to use a chemical solvent to increase the yield of juice extraction. Hence, this study will peruse distilled water as our extraction solvent.

Ozone meanwhile has been recognized as a powerful oxidant (1.5 times stronger than chlorine) and has been widely used in food and beverage industries with aims to protect the food products against its pertinent microorganisms and assure the retention of sensory, nutritional and physicochemical characteristic (Prabha et al., 2015). Ozone is a very pungent bluish gas readily degrades, as it is unstable and decomposes in a very short time but has a longer half-life in the gaseous state than in aqueous solution (Prabha et al., 2015). Ozone can be generated continuously either by corona discharge, ultraviolet radiation, or electrolysis method (Nath et al., 2014; Prabha et al., 2015). The by-product of ozone, when it decomposes is oxygen; so food products treated with ozone are free of disinfectant residue (Prabha et al., 2015). In 1997, the United States Food and Drug Administration (USFDA) has declared that ozone as Generally Regarded As Safe (GRAS) for use in food processing. Thus, a number of commercial fruit juice processors in the USA have started to employ ozone to meet the recent FDA mandatory 5-log reduction of the most resistant pathogens in their finished products (Cullen et al., 2009).

The application of gaseous ozone treatment of orange juice resulted in Escherichia coli population reduction of 5-log cycles (Patil et al., 2010). In addition, Steenstrup and Floros (2004) observed a rapid inactivation of $E$. coli $\mathrm{O} 157: \mathrm{H} 7$ in apple cider when treated with $860 \mathrm{ppm}(\mathrm{v} / \mathrm{v})$. Another author observed 6$\log$ reduction of E. coli $\mathrm{O} 157: \mathrm{H} 7$ in apple cider and orange juice when treated with $0.9 \mathrm{~g} / \mathrm{h}$ ozone under mild heating of $50^{\circ} \mathrm{C}$ (Williams et al., 2004). However, the efficacy of ozone depends not only on the quantity used but also on the residual ozone in the air, air $\mathrm{pH}$, temperature, humidity, and the amount of organic matter surrounding the cells (Patil and Bourke, 2012). The authors also stressed that ozone is not universally beneficial and, in some cases, may promote oxidative spoilage in foods, if used excessively (Chawla et al., 2012; Prabha et al., 2015). Ozone treatment on fruit juice is expected to cause the loss of anthocyanin, ascorbic acid, phenolic content, changes to the rheology, and colour due to its strong oxidizing activity. Hence, for effective and safe use in food processing, optimum ozone concentration, contact time and other treatment conditions should be defined for Roselle fruit juice with 
the aim to retain its nutritional qualities. Therefore, the objectives of this study were to determine the optimum parameters of Roselle fruit juice extraction by using ultrasound and to determine the effect of gaseous ozone on the physicochemical characteristics of Roselle fruit juice.

\section{Materials and methods}

2.1 Extraction yield of Roselle fruit juice using ultrasonication method

Fresh Roselle calyxes were purchased from a commercial farm in Johor, Malaysia. Roselle calyxes were first washed with distilled water and cut into small pieces $(\sim 2 \mathrm{~cm})$. Samples of $15 \mathrm{~g}$ Roselle calyxes were placed into $100 \mathrm{~mL}$ beaker. Roselle was suspended with distilled water with the weight ratio of Roselle to water was 1:2 (Chumsri et al., 2008). The ultrasonic probe was placed into the beaker and ultrasonic treatment was performed at a frequency of $20 \mathrm{kHz}$ with a power of 200 $\mathrm{W}$ for different processing time $(0,2,4,6$, and 8 mins $)$. The procedure was carried out at ambient temperature and the sonication processing temperature was controlled using a water-bath filled with ice cubes and a temperature probe for monitoring purpose. At the end of the ultrasound treatment, the sample was filtered through a wire mesh sieve. The procedure was then repeated by changing the sonication processing temperature to 10 , 20,30 , and $40^{\circ} \mathrm{C}$. The ultrasound power and treatment time was $20 \mathrm{kHz}$ and $2 \mathrm{~min}$, respectively. The extraction yield was calculated using Equation 1;

Extraction yield $(\%)=\frac{(\text { Amount of juice recovered }(\mathrm{g}))}{(\text { Amount of initial mixture }(\mathrm{g}))} \times 100$

The samples were then kept in a High-Density Polyethylene (HDPE) bottles and placed in a deep freezer $\left(-40^{\circ} \mathrm{C}\right)$ before further tests are done (within three days).

\subsection{Design of experiment on ultrasonication variables}

The quadratic central composite circumscribed response surface design was used to determine the optimal sonication temperature and time to maximize the extraction yield of Roselle fruit juice. Five levels of independent variables and software Design Expert Version (Vers. 11 Stat Ease Inc, MN, USA) were used to generate the experimental design and to analyze data. The complete design consisted of 13 experimental points including 4 factorial points, 4 axial points and 5 centre points. The extraction yield in Roselle fruit juice with and without ultrasonic extraction (control samples) was compared.

\subsection{Preparation of Roselle fruit juice for ozone treatment}

The previously extracted Roselle fruit juice was thawed in the refrigerator $\left(4^{\circ} \mathrm{C}\right)$ for $24 \mathrm{hrs}$ before ozone treatment was conducted on the samples. Roselle fruit juice was divided into two categories, which is Filtered I and Filtered II. Filtered I indicate that the Roselle fruit juice was filtered through a wire mesh sieve after ultrasound treatment. Filter II indicates that the filtered Roselle fruit juice after ultrasound treatment was centrifuged at $6500 \mathrm{rpm}$ for 10 mins by centrifuge (Universal 320) and then filtered again through a cloth mesh to remove the pulp.

\subsection{Ozone treatment}

Ozone gas was generated in a closed system using water ozonizer (Model SY- 004, Taiwan) by corona discharge method in a $500 \mathrm{~mL}$ beaker. The fixed ozone output concentration at $600 \mathrm{mg} / \mathrm{h}$ was measured using an ozone sensor (Model 200 Series, Aeroqual, New Zealand). The delivery tube was then connected to the ozone generator. Ozone gas was directly flowed into the juice (Filtered I and Filtered II) for 0, 10, 20, and 30 mins through a food-grade silicone tube into the beaker and stirred using a magnetic stirrer (100 rpm) to ensure the ozone molecules were homogenized with the samples. The gas flow rate was fixed at $0.2 \mathrm{~L} / \mathrm{min}$ and the treatment temperature was fixed at $20^{\circ} \mathrm{C}$. The experiment was conducted in a laminar airflow cupboard to prevent excessive exposure of ozone gas. All experiments were carried out in triplicates and analyses were immediately performed after processing (within an hour).

\subsection{Physicochemical analysis}

\subsection{1 pH}

The $\mathrm{pH}$ of Roselle fruit juice was determined by using $\mathrm{pH}$ meter (SevenMulti $\mathrm{pH}$ Conductivity Meter, Mettler Toledo, Switzerland) and it was calibrated with standard buffer solutions of $\mathrm{pH} 4$ and 7 . About $10 \mathrm{~mL}$ of Roselle fruit juice was prepared in a beaker and an electrode was submerged directly in the sample solution until a steady reading is reached.

\subsubsection{Titratable acidity (TA)}

Titratable acidity of Roselle fruit juice was determined by titration using a $\mathrm{pH}$ meter (Youssef et al., 2015). pH meter was calibrated with standard buffer solutions of $\mathrm{pH} 4$ and 7. Distilled water with $100 \mathrm{~mL}$ was placed into a $250 \mathrm{~mL}$ beaker. The $\mathrm{pH}$ of water was adjusted to 8.1 by adding $0.1 \mathrm{~N}$ sodium hydroxide, $\mathrm{NaOH}$. Then, Roselle fruit juice with $5 \mathrm{~mL}$ was added into beaker and stirred. The mixture is titrated to a $\mathrm{pH}$ of 8.2 by slowly adding $0.1 \mathrm{~N} \mathrm{NaOH}$. The volume of $0.1 \mathrm{~N}$ $\mathrm{NaOH}$ was recorded. Percentage of citric acid content was calculated using Equation 2; 
Titratable acid $(\%, w / w)=\frac{(\text { Net ml Titrant })(\mathrm{N} \text { Titrant })}{(\mathrm{g} \text { Sample })} \times 6.4$

\subsubsection{Total colour difference (TCD)}

CIE (Commision Internationale de l'éclairage) Lab scale: L* (lightness, 0 - 100), a* (green to red) and $b^{*}$ (blue to yellow) of Roselle fruit juice were determined in a HunterLab Ultra Scan Pro (D65, HunterLab Assoc Lab Inc, Reston, VA, USA). For colour determination, the colourimeter was previously calibrated using black and white mosaics. Triplicate measurements were taken for each set of samples and values of $\mathrm{L}^{*}, \mathrm{a}^{*}$, and $\mathrm{b}^{*}$ were recorded. Total colour difference (TCD) indicates the magnitude of colour change after treatment was calculated using Equation 3;

$$
\mathrm{TCD}=\sqrt{\left(\mathrm{L}^{*}-\mathrm{L}_{0}{ }^{*}\right)^{2}+\left(\mathrm{a}^{*}-\mathrm{a}_{0}^{*}\right)^{2}+\left(\mathrm{b}^{*}-\mathrm{b}_{0}{ }^{*}\right)^{2}}
$$

Where $\mathrm{L}_{0}, \mathrm{a}_{0}, \mathrm{~b}_{0}=$ initial values obtained from untreated juice.

\subsubsection{Ascorbic acid (AA)}

Ascorbic acid of Roselle fruit juice was determined by reducing 2,6-dichlorophenol-indophenols solution from a blue colour to a colourless or very faint endpoint with the addition of ascorbic acid (Youssef et al., 2015). Dye solution with $0.5 \%$ was prepared by dissolving $0.042 \mathrm{~g}$ of sodium hydrogen carbonate, $\mathrm{NaHCO}_{3}$ in distilled water and adding $0.050 \mathrm{~g}$ of sodium 2,6dichloroindolphenol. When the dye was dissolved, makeup to $200 \mathrm{~mL}$. To prepare ascorbic acid standard solution $(1 \mathrm{mg} / \mathrm{mL}), 0.100 \mathrm{~g}$ of ascorbic acid was placed into a $100 \mathrm{~mL}$ volumetric flask and dilute to $100 \mathrm{~mL}$. Then, $10 \mathrm{~mL}$ of dye solution was transferred to a beaker. Ascorbic acid solution was added drop by drop into dye solution using a Beral-type pipet and stirred. The number of drops added into the dye solution was counted when the colour changes from blue to the very light amber endpoint. Next, the procedure was repeated using Roselle fruit juice. All the experiments were carried out in triplicate. The concentration of ascorbic acid content was calculated using Equation 4;

Ascorbic acid $\left(\frac{\mathrm{mg}}{100 \mathrm{~mL}}\right)=\frac{\text { (Drops of standard) } \text { (Concentration of standard) }}{\text { (Drops of fruit juice) }} \times 100$

\subsubsection{Total phenolic content (TPC)}

Total phenolic content of Roselle fruit juice was determined according to the Folin-Ciocalteu procedure that was adopted from Youssef et al. (2015). FolinCiocalteu reagent $(10 \%)$ with $1.5 \mathrm{~mL}$ was mixed with $1.2 \mathrm{~mL}$ of $7.5 \%$ sodium carbonate, $\mathrm{Na}_{2} \mathrm{CO}_{3}$ solution, then $0.3 \mathrm{~mL}$ of Roselle juice sample was added. The test tubes were allowed to stand for one hour at ambient temperature, and the absorption was measured $765 \mathrm{~nm}$ using a spectrophotometer (Ultraspec 3100 Pro, Amersham Pharmacia Biotech, UK) against a blank. All the experiments were carried out in triplicate. TPC was obtained from the calibration curve prepared with gallic acid at concentrations of $0,50,100,150,250$ and 500 $\mathrm{mg} / \mathrm{L}$.

\subsubsection{Total anthocyanin content (TAC)}

The total anthocyanin content of Roselle fruit juice was measured using a spectrophotometric $\mathrm{pH}$ differential protocol (Wu et al., 2006). The Roselle fruit juice was thoroughly mixed with $0.025 \mathrm{M}$ potassium chloride $(\mathrm{pH}$ 1.0). The absorbance of the mixture was measured at 515 and $700 \mathrm{~nm}$ using distilled water to zero the spectrophotometer. The Roselle fruit juice was then combined with $0.4 \mathrm{M}$ sodium acetate buffer $(\mathrm{pH} 4.5)$, and the absorbances were measured at the same wavelengths. The absorbance of the diluted sample (A) was calculated using Equation 5;

$$
\mathrm{A}=\left(\mathrm{A}_{515}-\mathrm{A}_{700}\right) \mathrm{pH} 1.0-\left(\mathrm{A}_{515}-\mathrm{A}_{700}\right) \mathrm{pH} 4.5
$$

The anthocyanin content was calculated using Equation 6;

Total anthocyanin content $(\mathrm{mg} / \mathrm{l})=\frac{\mathrm{A} \times \mathrm{MW} \times \mathrm{DF} \times 1000}{\varepsilon \times 1}$

Where $\mathrm{A}=$ absorbance of the diluted sample, $\mathrm{DF}=$ dilution factor, $\mathrm{MW}=449.2, \varepsilon=26,900$

Since the sample composition was unknown, pigment content was calculated as cyanidin- 3-glucoside.

\section{Results and discussion}

\subsection{Impact of sonication variables on extraction yield in} Roselle fruit juice

The impact of ultrasonic time on the extraction yield in Roselle fruit juice is shown in Figure 1a. The extraction yield in Roselle fruit juice after 4 mins had increased by $11.41 \%(\mathrm{P}<0.05)$ in comparison with the control samples. However, extraction yield in Roselle fruit juice was found to decrease when sonication treatment was prolonged for more than 4 mins. Longer treatment time did not make significant differences $(\mathrm{P}>0.05)$ in extraction yield as in agreement with the study of Nguyen and Le (2012). The authors had stated that longer sonication time had reduced both antioxidant levels and activity of the fruit juice. It was also in accordance with the statement by Phan et al. (2012) that longer sonication time can generate a high level of hydroxyl radicals and that can lead to a negative impact on the juice quality. Therefore, the appropriate ultrasonic time to achieve maximum extraction yield in this study was 4 min. Nguyen and Le (2012) in their study had found that the sonication time for the extraction of pineapple mash was only 2 mins, whereas, the ultrasonic treatment for maximizing total phenolic and ascorbic 
acid from rose myrtle mash was 6 min (Vo and Le, 2014). Consequently, the efficacy of ultrasonic extraction can be theorized on the physical structure (cell wall) of the fruits treated. The highly recalcitrant structure of lignocellulose (cellulose, lignin, and hemicellulose) creates protective armors from the physical impact of acoustic cavitation (Pozos et al., 2020). It was also reiterated by Lieu and Le (2010) that the optimal sonication time depends on sonication temperature, and weight of plant material used in the experiment.

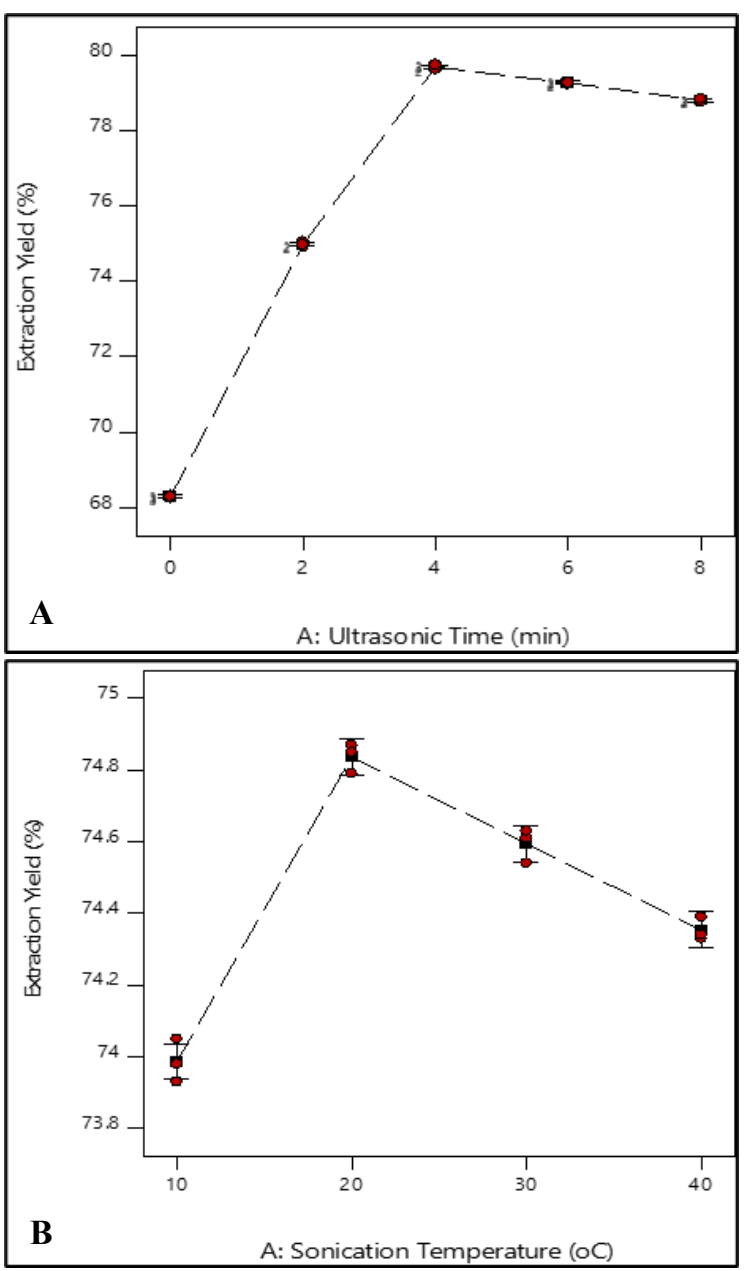

Figure 1. Effect of (a) ultrasonic time and (b) temperature on extraction yield of Roselle fruit juice.

Figure $1 \mathrm{~b}$ also depicts the effect of sonication temperature on the extraction yield in Roselle fruit juice. When the treatment temperature increased from $10^{\circ} \mathrm{C}$ to $20^{\circ} \mathrm{C}$, the extraction yield increased from 73.99 to $74.84 \%(\mathrm{P}<0.05)$. Between the temperature range of 20 to $40^{\circ} \mathrm{C}$, the extraction efficacy had reduced by 0.3 to $0.6 \%(\mathrm{P}<0.05)$. The increase in temperature causes the vapour pressure to increase while decreasing the viscosity of treated juice allowing for violent collapse of bubbles. Thus, the optimum temperature at which the viscosity and temperature are low enough to form violent cavitation bubbles and prevent the dampening effect on bubble collapse should be identified to optimize the yield of extraction (Tiwari, 2015; Chemat et al., 2017). In this study, it was found that the optimized sonication temperature in which the yield of extraction is at the highest is at $20^{\circ} \mathrm{C}$. Chemat et al. (2017), also reported that the degree of cavitation effects depends on the structure of plant tissue, plasticity, and its chemical composition. Lieu and Le (2010) in their study found that the optimal temperature that produced the highest yield is at $70^{\circ} \mathrm{C}$. However, it needs to be noted that the ultrasonic treatment on grape mash was supplemented with a pectin enzyme that aids in breaking the cell wall of grapefruit. Therefore, the optimal sonication temperature can be varied in a large range depending on the type of final product one expects. In our study, it was aimed that the fruit juice should be produced at the temperature of below $40^{\circ} \mathrm{C}$ to adhere to non-thermal processing rules. Thus, it can also be concluded that Roselle extraction in this study is able to produce at the same output (at $\sim 80 \%$ extraction yield) at a low sonication temperature $\left(20^{\circ} \mathrm{C}\right.$ as opposed to $\left.70^{\circ} \mathrm{C}\right)$ which required lower energy input in comparison to the findings of Lieu and Le (2010).

\subsection{Optimization of sonication conditions for maximizing the extraction yield of Roselle fruit juice by RSM}

Based on the results of the previous sections, ultrasonic time of $4 \mathrm{~min}$ and sonication temperature of $20^{\circ} \mathrm{C}$ was selected as the central conditions of the optimization experiment. Table 1 shows the experimental design and results of the extraction yield of Roselle fruit juice. Multiple regression analysis was performed on the experimental data and the coefficients of the model were evaluated for their significance. Results showed that the linear coefficients (A, B) and the pure quadratic coefficients (A2, B2) were significant $(\mathrm{P}<0.05)$. The cross product coefficient $(\mathrm{AB})$ was eliminated in the refined equation as its effect was not significant $(\mathrm{P}>0.05)$. The final predictive Equation 7 obtained was as follow;

Extraction yield $=79.69+0.8966 \mathrm{~A}+0.9073 \mathrm{~B}-3.35 \mathrm{~A}^{2}-$ $1.72 \mathrm{~B}^{2}(7)$

Where A, B were sonication temperature and time, respectively. The analysis of variance of the fitted model was performed. The coefficient of determination $\left(\mathrm{R}^{2}\right)$ of the model is 0.9735 which indicated that a reasonable agreement between the experimental and the predicted values.

The surface response graph of Equation 7 is illustrated in Figure 2. Based on the results, the change in sonication temperature and time had a significant positive effect $(\mathrm{P}<0.05)$ on the extraction yield of Roselle fruit juice. According to the model, the extraction yield of Roselle fruit juice achieved a maximum of $79.86 \%$ at an optimal sonication 
temperature of $22^{\circ} \mathrm{C}$ and ultrasonic time of 4.4 mins. Three independent replicates were carried out for measuring the extraction yield of Roselle fruit juice under the optimal conditions in order to verify the accuracy of the model. The experiment showed that the average extraction yield of Roselle fruit juice was $79.81 \%$. The predicted and experimental values were nearly similar. Moreover, a control sample without ultrasonic treatment was observed with an extraction yield of $68.28 \%$. Thus, the application of sonication to Roselle fruit juice had increased the extraction yield of $11.53 \%$ higher in comparison with the control sample.

Table 1. Experiment design and results of extraction yield of Roselle fruit juice from ultrasound-assisted extraction.

\begin{tabular}{ccccc}
\hline & & Factor 1 & Factor 2 & Response 1 \\
\cline { 3 - 5 } Std & Run & $\begin{array}{c}\text { A: Ultrasonic } \\
\text { Temperature } \\
\left({ }^{\circ} \mathrm{C}\right)\end{array}$ & $\begin{array}{c}\text { B: Ultrasonic } \\
\text { Time } \\
(\mathrm{min})\end{array}$ & $\begin{array}{c}\text { Extraction } \\
\text { Yield } \\
(\%)\end{array}$ \\
\hline \multicolumn{2}{c}{ Control } & 0 & 0 & 68.28 \\
1 & 12 & 10 & 2 & 73.95 \\
2 & 9 & 30 & 2 & 74.59 \\
3 & 10 & 10 & 6 & 74.23 \\
4 & 5 & 30 & 6 & 75.94 \\
5 & 4 & 5.85786 & 4 & 71.23 \\
6 & 3 & 34.1421 & 4 & 74.64 \\
7 & 2 & 20 & 1.17157 & 74.21 \\
8 & 13 & 20 & 6.82843 & 78.19 \\
9 & 6 & 20 & 4 & 79.67 \\
10 & 1 & 20 & 4 & 79.77 \\
11 & 7 & 20 & 4 & 79.72 \\
12 & 11 & 20 & 4 & 79.65 \\
13 & 8 & 20 & 4 & 79.62 \\
\hline
\end{tabular}

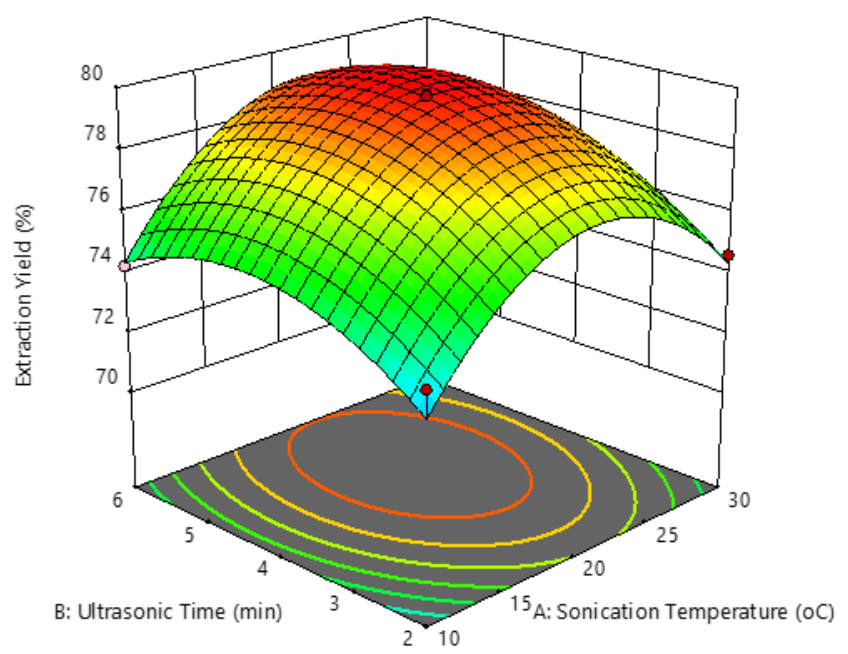

Figure 2. Quadratic modeling of ultrasonic time and temperature on the extraction yield of Roselle fruit juice.

\subsection{Effect of ozone treatment on physicochemical characteristics of Roselle fruit juice}

\section{$3.3 .1 \mathrm{pH}$}

In this study, the $\mathrm{pH}$ value of ozonated Roselle fruit juice was ranged from 2.35 to 2.40 for Filtered I whereas 2.38 to 2.44 for Filtered II within the range recommended by the FDA Standard (a maximum $\mathrm{pH}$ 3) (FDA, 2001). An ANOVA for $\mathrm{pH}$ determination showed both independent variables (juice sample and processing time) were not significant $(\mathrm{P}>0.05)$. Similar results were also observed in ozonated strawberry juice (Tiwari et al., 2009a), blackberry juice (Tiwari, O'Donnell, Muthukumarappan et al., 2009), grape juice (Tiwari et al., 2009b) and orange juice (Tiwari et al., 2008) which showed no significant change on $\mathrm{pH}$ value over the ozone treatment time. In contrast, previous findings found that there were no significant changes in $\mathrm{pH}$ value for Roselle fruit juice which pasteurized at $75^{\circ} \mathrm{C}$ for $15 \mathrm{~s}$ and $70^{\circ} \mathrm{C}$ for 25 mins, respectively (Ramírez-Rodrigues et al., 2012). Therefore, ozone treatment can preserve fruit juice by maintaining the $\mathrm{pH}$ at a low value in order to prevent the microbial growth in fruit juice.

Nevertheless, Filtered I Roselle fruit juice showed lower $\mathrm{pH}$ value in comparison with Filtered II Roselle fruit juice, as shown in Figure 3a. This can be explained by the hydrolysis of methyl esters by pectin methylesterase (PME) in fruit juice results in the formation of acidity. Furthermore, Filtered I Roselle fruit juice may contain more pectin than Filtered II Roselle fruit juice. Therefore, it was believed that the PME activity in Filtered I Roselle fruit juice is higher giving a lower $\mathrm{pH}$ value than Filtered II Roselle fruit juice. This finding is in agreement with a study by Anthon and Barrett (2012) who observed that de-esterification of pectin by PME in tomato juice caused the drop of $\mathrm{pH}$ value with the increase of methanol concentration.

\subsubsection{Titratable acidity (TA)}

Titratable acidity (TA) of Roselle fruit juice was expressed as the percentage of citric acid. TA of Roselle fruit juice for Filtered I was within the range of 0.7168 $0.768 \%$ whereas TA for Filtered II which lies between $0.7424-0.8064 \%$. Based on the ANOVA analysis, ozone treatment had no significant effect $(\mathrm{P}>0.05)$ on TA in Roselle fruit juice. This finding was in agreement with ozonated strawberry juice (Tiwari et al., 2009a), blackberry juice (Tiwari, O'Donnell, Muthukumarappan et al., 2009), grape juice (Tiwari et al., 2009b) and orange juice (Tiwari et al., 2008) which showed no change on TA over the ozone treatment time. In comparison with thermal pasteurization, Mashkour et al. (2013) also reported that Roselle fruit juice showed no significant difference in TA after pasteurized at $85^{\circ} \mathrm{C}$ for 10 mins. A similar result was also observed by RamírezRodrigues et al. (2012) where the Roselle fruit juice was pasteurized at $75^{\circ} \mathrm{C}$ for $15 \mathrm{~s}$. Hence, it showed that ozone treatment and pasteurization have a positive effect on preserving the TA of fruit juices.

Furthermore, TA of Filtered I Roselle fruit juice was 

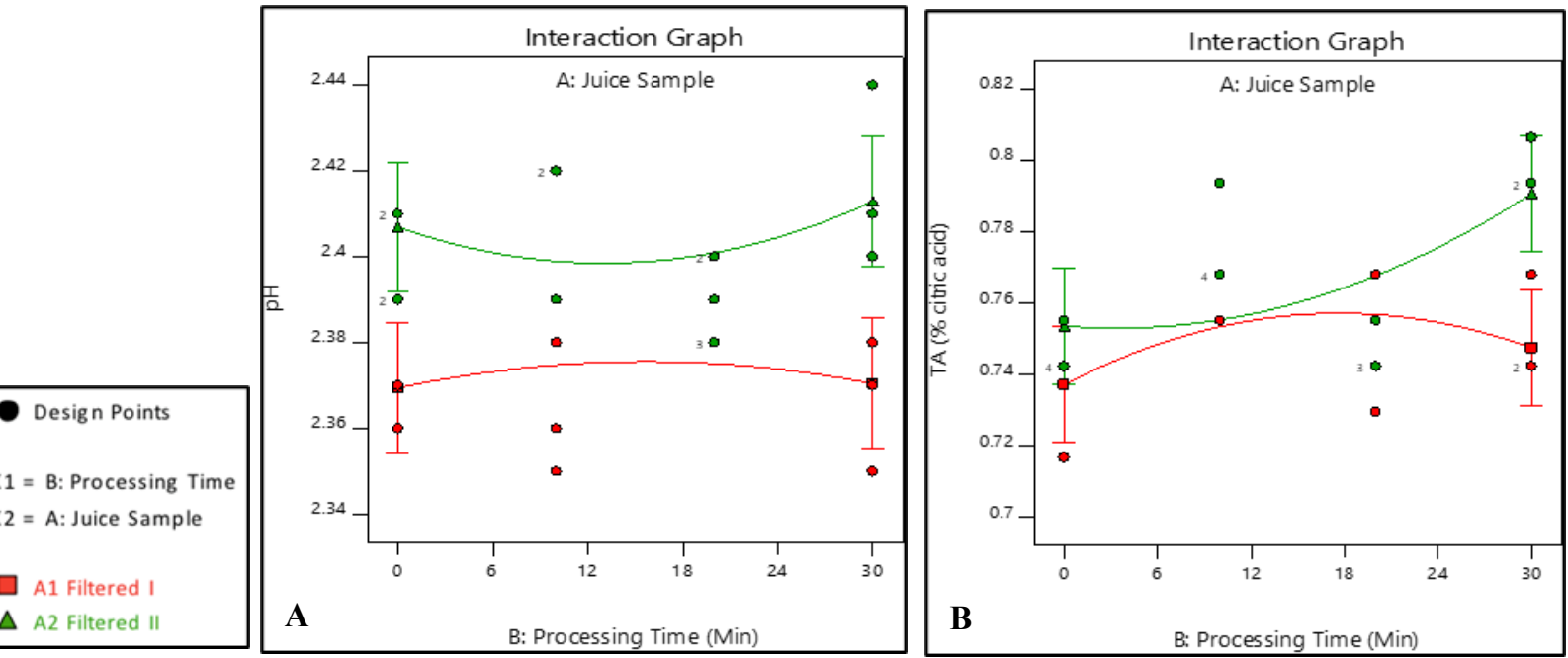

Figure 3. Interaction graph of juice sample and processing time on (a) $\mathrm{pH}$ and (b) TA.

slightly lower than Filtered II Roselle fruit juice, as illustrated in Figure 3b. Plotto et al. (2008) reported a similar trend of citric and malic acid that was found lower in juice with pulp as compared with filtered juice, thus explaining the perception of latter juice tasting sweeter. Titratable acidity is responsible for tasting sensation, for instance, too much acidity may render the juice or cider too sharp and unpleasant to drink.

\subsubsection{Total colour difference (TCD)}

TCD values were found to be significantly influenced by processing time $(\mathrm{P}<0.0001)$. A trend towards increased TCD values for both types of Roselle fruit juice at increasing ozone processing time was observed, as illustrated in Figure 4a. Similar results have been observed in ozonated apple juice (Torres et al., 2011), strawberry juice (Tiwari et al., 2009a), blackberry juice (Tiwari, O'Donnell, Muthukumarappan et al., 2009), grape juice (Tiwari et al., 2009b) and orange juice (Tiwari et al., 2008) which showed significant colour degradation over the ozone treatment time. On the other hand, Zaman et al. (2017) reported that thermal treatment $\left(90^{\circ} \mathrm{C}\right.$ for $\left.2 \mathrm{~min}\right)$ of extracted Roselle fruit juice showed a massive decrement with $\mathrm{L}^{*}$ (lightness) due to heating caused the accumulation of the dark colour compound in juice. Mgaya et al. (2014) in his study also found that Roselle fruit juice which was pasteurized at $82.5^{\circ} \mathrm{C}$ for 20 mins obtained $\mathrm{L}^{*}$ value of 14.3 , which was lower compared to the finding of this study with $L^{*}$ value ranging from 19.4 to 22.8 . Both ozone treatment and thermal pasteurization result in significant degradation of fruit colour.

Nevertheless, TCD value for Filtered II Roselle fruit juice was higher than Filtered I Roselle fruit juice. SteinChisholm (2015) stated that filtered juices retained less anthocyanidins from raw due to the removal of copigmentation of anthocyanins by filtration. It can be related to the decreasing trend of anthocyanin (TAC) which gave a lower TAC value in Filtered II Roselle fruit juice, as shown in Figure 4b. Therefore, Filtered II Roselle fruit juice had higher TCD value than Filtered I Roselle fruit juice after ozone treatment.

\subsubsection{Total anthocyanin content (TAC)}

ANOVA for anthocyanin (TAC) determination of Roselle fruit juice showed statistical significant effect $(\mathrm{P}<0.05)$ by both independent variables; juice sample and processing time. Filtered I Roselle fruit juice retained more anthocyanidins from raw than Filtered II

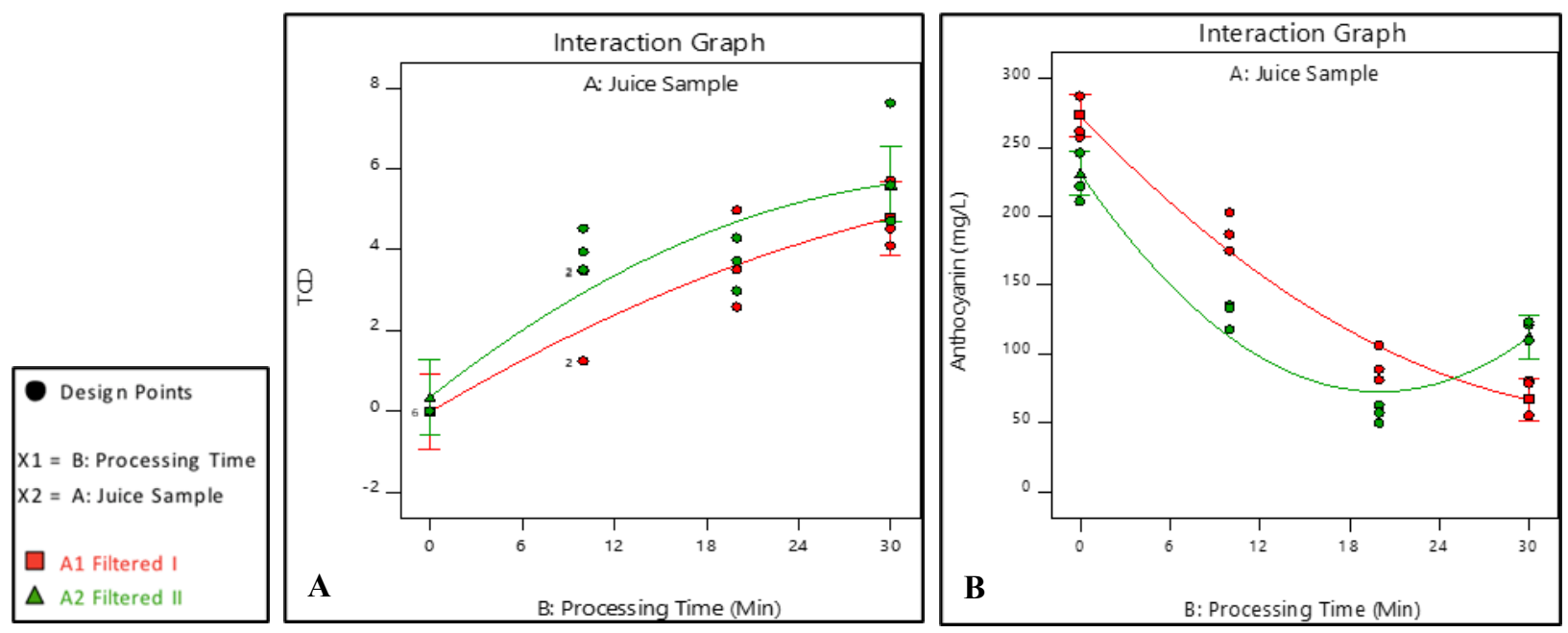

Figure 4. Interaction graph of juice sample and processing time on (a) TCD and (b) TAC. 
Roselle fruit juice due to the removal of copigmentation of anthocyanins by filtration (Stein-Chisholm, 2015). Figure $4 \mathrm{a}$ showed that the TAC value of Filtered I Roselle fruit juice decreased significantly from 268.57 to $71.38 \mathrm{mg} / \mathrm{L}(73.42 \%)$ over $30 \mathrm{mins}$ of ozone treatment. Filtered II Roselle fruit juice decreased from 226.02 to $56.54 \mathrm{mg} / \mathrm{L}(74.98 \%)$ over $20 \mathrm{mins}$ of ozone treatment, but increased again to $117.89 \mathrm{mg} / \mathrm{L}$ after 30 mins of ozone treatment. This finding was in agreement with the reduction of $98.2 \%$ in anthocyanin of strawberry juice (Tiwari et al., 2009a) and 78.0\% in anthocyanin of grape juice (Tiwari et al., 2009b) with increasing treatment time and ozone concentration. Nevertheless, the increase of anthocyanin of Filtered II Roselle fruit juice after 30 min of ozone treatment is unknown. Previous studies by Tiwari et al. (2009a) have shown that degradation of anthocyanin of ozone-treated fruit juice is expected. Degradation of anthocyanin undergo oxidative cleavage either to direct reaction with ozone or indirect reaction due to the formation of intermediate radicals (Cullen et al., 2009). Thus, the formation of ozonide broken down the aromatic ring and degradation efficiency rises quickly (Tiwari et al., 2009a; Tiwari et al., 2009b).

\subsubsection{Ascorbic acid (AA)}

The initial value of ascorbic acid (AA) was 74.51 $\mathrm{mg} / 100 \mathrm{~mL}$ and it reduced to $55.38 \mathrm{mg} / 100 \mathrm{~mL}$ $(25.67 \%)$ for Filtered I Roselle fruit juice while for Filtered II Roselle fruit juice, the initial value of AA was $73.08 \mathrm{mg} / 100 \mathrm{~mL}$ and it had reduced to $52.17 \mathrm{mg} / 100$ $\mathrm{mL}(28.61 \%)$. ANOVA analysis showed that significant effect $(\mathrm{P}<0.05)$ was found by both independent variables - juice sample and processing time. Figure 5a showed that the AA content for both types of Roselle fruit juice decreased significantly throughout the ozone processing time. In contrast, thermal treated $\left(90^{\circ} \mathrm{C}\right.$ for 2 mins) Roselle fruit juice showed a reduction in ascorbic acid content about $42 \%$ reported by Zaman et al. (2017), which was greater than both ozonated Filtered I and Filtered II Roselle fruit juice. In addition, a previous study found that Roselle fruit juice resulted in a significant reduction in ascorbic acid of about $53.41 \%$ after pasteurization at $70^{\circ} \mathrm{C}$ for 25 mins (Egbere et al., 2007). Therefore, it proved that ozone treatment preserved the better quality of Roselle fruit juice with respect to ascorbic acid content than thermal pasteurization. Moreover, degradation of AA in Roselle fruit juice was lower than $50 \%$ which means it can prolong the shelf life of juice.

Nevertheless, AA of Filtered I Roselle juice was higher than Filtered II Roselle fruit juice due to the removal of antioxidant compound by filtration. Degradation of ascorbic acid is caused by the formation of free hydroxyl radicals by photochemical reaction, related to oxidative processes (Santhirasegaram et al., 2015). In addition, the presence of oxygen, light, and enzyme activities such as ascorbate oxidase and peroxidase contribute to detrimental effects on ascorbic acid (Santhirasegaram et al., 2015).

\subsubsection{Total phenolic content (TPC)}

From the statistical analysis of data, it showed that sample juice and processing time affected significantly $(p<0.05)$ the TPC value of Roselle fruit juice. Figure $5 \mathrm{~b}$ shows that the TPC value of Filtered I Roselle fruit juice decreased significantly from 402.25 to $257.80 \mathrm{mg} / \mathrm{L}$ GAE while for Filtered II Roselle fruit juice decreased from 300.58 to $153.36 \mathrm{mg} / \mathrm{L}$ GAE over $30 \mathrm{mins}$ of ozone treatment. Similarly, the treatment of ozonated apple juice for $10 \mathrm{~min}$ resulted in a significant reduction in TPC value (Patil et al., 2010). The degradation of polyphenol is due to the strong oxidative potential of ozone, resulting in direct reaction with target compounds or its intermediates and radical reactions between hydroxyl radicals through ozone decomposition catalyzed mainly by the hydroxide ion (Cullen et al., 2009; Patil et al., 2010; Torres et al., 2011). According to Ramírez-Rodriguez et al. (2012), TPC value of Roselle fruit juice after $\mathrm{HTST}\left(75^{\circ} \mathrm{C}\right.$ for $\left.15 \mathrm{~s}\right)$ was 50.79
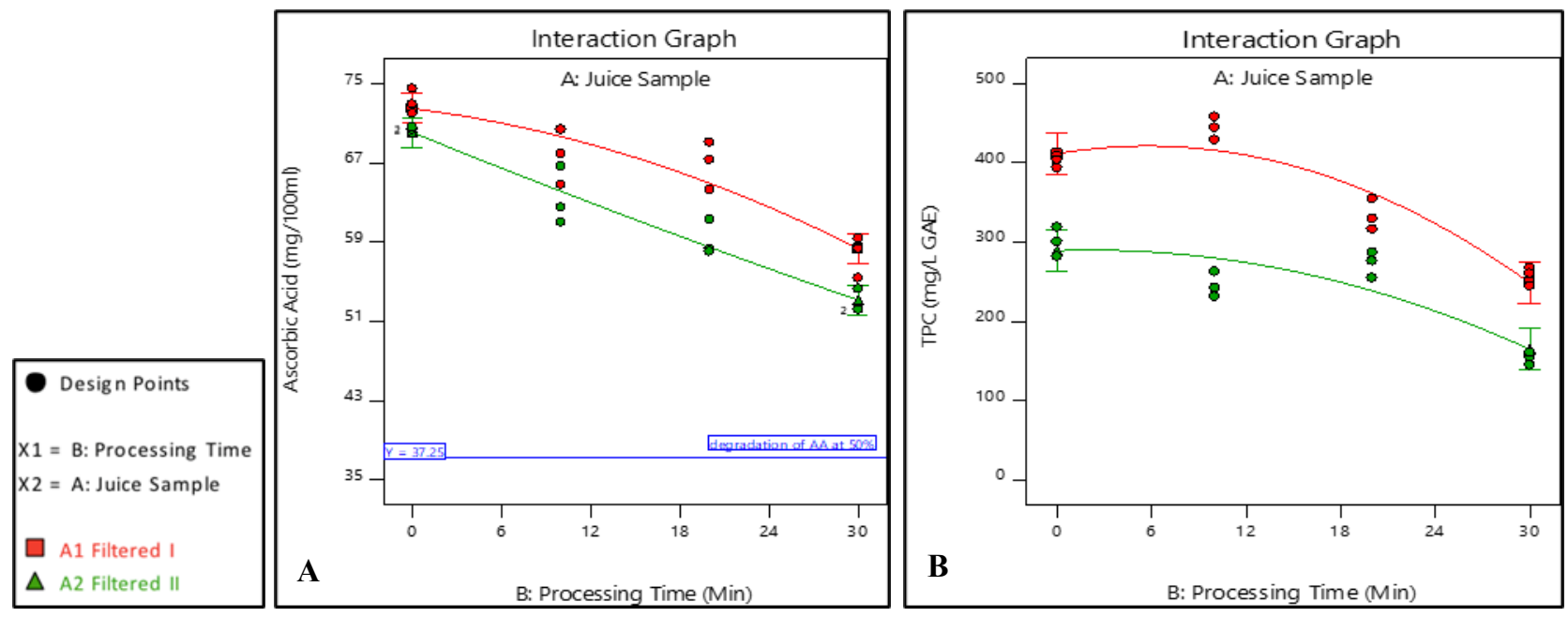

Figure 5. Interaction graph of juice sample and processing time on (a) AA and (b) TPC. 
$\mathrm{mg} / \mathrm{L}$, which is much lower than this study.

However, TPC value in Filtered I and Filtered II Roselle fruit juice had increased slightly after $10 \mathrm{~min}$ and $20 \mathrm{~min}$ of ozone treatment, respectively $(\mathrm{P}<0.05)$. The increase of TPC value due to ozone treatment was also in agreement with the findings of Onopiuk et al. (2017), where the polyphenolic content in pineapples and bananas increased significantly after 20 mins exposure to ozone. This increment may be caused by the activation of phenylalanine ammonium lyase (PAL), an enzyme can be stimulated by different abiotic stresses besides wounding (Onopiuk et al., 2017). PAL is an enzyme participating in the synthesis of phenolic compounds in plant tissues. Furthermore, several studies have reported that the presence of ozone may contribute to the inhibition of enzymes such as polyphenolic oxidase (PPO) and peroxidase (POD), which often cause oxidation of phenolic compounds (Onopiuk et al., 2017).

\section{Conclusion}

Application of ultrasound enhanced extraction yield of Roselle fruit juice $11.53 \%$ higher in comparison with the control at optimal sonication temperature of $22^{\circ} \mathrm{C}$ and ultrasonic time of $4.4 \mathrm{~min}$. However, further studies are required to clarify the effects of sonication variables (ultrasonic power, medium properties, and operating frequency) on the extraction yield of Roselle fruit juice. No significant differences $(\mathrm{P}>0.05)$ in $\mathrm{pH}$ and $\mathrm{TA}$ of Roselle fruit juice were observed in ozone-treated samples. However, ozone treatment was found to have significant effects $(\mathrm{P}<0.05)$ on TCD, AA, TPC, and TAC. Nevertheless, ozone treatment showed lower degradation of ascorbic acid as compared to thermal pasteurization (differences by 13\%). From this study, ozonated Filtered I Roselle fruit juice was found to retain higher nutrients than Filtered II Roselle fruit juice $(\mathrm{P}<0.05)$. Even so, the effect of ozone treatment on inactivation of microorganisms is needed to be determined before ozone can be considered as an alternative preservation method. Other extrinsic and intrinsic parameters such as ozone concentration, temperature, ozone flow rate, and $\mathrm{pH}$ on ozone treatment warrant further study to determine the optimal condition for the preservation of fruit juice.

\section{Conflict of interest}

The authors declare no conflict of interest.

\section{Acknowledgments}

The authors would like to acknowledge the financial and infrastructural support provided by Universiti Putra Malaysia (IPM. 9491300)) under GP-IPM grants.

\section{References}

Agcam, E., Akyildiz, A. and Dundar, B. (2018). Thermal pasteurization and microbial inactivation of fruit juices. In Rajauria, G. and Tiwari, B.K. (Eds). Fruit Juices, p. 309-339. USA: Elsevier. https:// doi.org/10.1016/B978-0-12-802230-6.00017-5

Ali, M.S. and Maryam, S. (2016). Ultrasound applications for the preservation, extraction, processing and quality control of food. BioTechnology: An Indian Journal, 12(4), 162-174.

Almahy, H.A., Abdel-Razik, H.H, El-Badry, Y.A. and Ibrahim, A.M. (2017). Ultrasound-assisted extraction of anthocyanin pigments from Hibiscus sabdariffa (Rosella) and its phytochemical activity at Kingdom of Saudi Arabia. International Journal of Chemical Sciences, 15(4), 196-204.

Ansari, M., Eslaminejad, T., Sarhadynejad, Z. and Eslaminejad, T. (2013). An overview of the Roselle plant with particular reference to its cultivation, diseases and usages. European Journal of Medicinal Plants, 3(1), 135-145. https://doi.org/10.9734/ EJMP/2013/1889

Anthon, G.E. and Barrett, D.M. (2012). Pectin methylesterase activity and other factors affecting $\mathrm{pH}$ and titratable acidity in processing tomatoes. Food Chemistry, 132(2), 915-920. https:// doi.org/10.1016/j.foodchem.2011.11.066

Aryanti, N., Nafiunisa, A. and Wardhani, D.H. (2019). Conventional and ultrasound-assisted extraction of anthocyanin from red and purple Roselle (Hibiscus sabdariffa L.) calyces and characterization of its anthocyanin powder. International Food Research Journal, 26(2), 529 - 535.

Ashokkumar, M. (2015). Applications of ultrasound in food and bioprocessing. Ultrasonics Sonochemistry, 25(1), 17-23. https://doi.org/10.1016/ j.ultsonch.2014.08.012

Bevilacqua, A., Petruzzi, L., Perricone, M., Speranza, B., Campaniello, D., Sinigaglia, M. and Corbo, M.R. (2018). Nonthermal technologies for fruit and vegetable juices and beverages: Overview and advances. Comprehensive Reviews in Food Science and Food Safety, 17(1), 2-62. https:// doi.org/10.1111/1541-4337.12299

Chawla, A.S., Kasler, D.R., Sastry, S.K. and Yousef, A.E. (2012). Microbial Decontamination of Food Using Ozone. In Demirci, A. and Ngadi, M.O. (Eds.). Microbial Decontamination in the Food Industry: Novel Methods and Applications. Cambridge, England: Woodhead Publishing Limited. https://doi.org/10.1533/9780857095756.3.495

Chemat, F., Rombaut, N., Sicaire, A.G., Meullemiestre, 
A., Fabiano-Tixier, A.S. and Abert-Vian, M. (2017). Ultrasound assisted extraction of food and natural products. Mechanisms, techniques, combinations, protocols and applications. A review. Ultrasonics Sonochemistry, 34, 540-560. https://doi.org/10.1016/ j.ultsonch.2016.06.035

Chumsri, P., Sirichote, A. and Itharat, A. (2008). Studies on the optimum conditions for the extraction and concentration of Roselle (Hibiscus sabdariffa Linn.) extract. Songklanakarin Journal of Science and Technology, 30(Suppl. 1), 133-139.

Cullen, P.J., Tiwari, B.K., O'Donnell, C.P. and Muthukumarappan, K. (2009). Modelling approaches to ozone processing of liquid foods. Trends in Food Science and Technology, 20(3-4), 125-136. https://doi.org/10.1016/j.tifs.2009.01.049

Da-Costa-Rocha, I., Bonnlaender, B., Sievers, H., Pischel, I. and Heinrich, M. (2014). Hibiscus sabdariffa L. - A phytochemical and pharmacological review. Food Chemistry, 165, 424 443. https://doi.org/10.1016/j.foodchem.2014.05.002

DOA (Department of Agriculture) (2017). Statistik tanaman negeri. Laporan tahunan Jabatan Pertanian Malaysia. Malaysia: DOA. [In Bahasa Malaysia].

Egbere, O.J., Anuonye, J.C., Chollom, P.F. and Okpara, P.V. (2007). Effect of some preservative techniques on the quality and storage stability of Zobo Drink (a Nigerian, non-alcoholic beverage from hibiscus sabdariffa). Journal of Food Technology, 5(3), 225 228.

Gonzalez-Centeno, M.R., Comas-Serra, F., Femenia, A., Rossello, C. and Simal, S. (2015). Effect of power ultrasound application on aqueous extraction of phenolic compounds and antioxidant capacity from grape pomace (Vitis vinifera L.): experimental kinetics and modeling. Ultrasonics Sonochemistry, 22, 506-514. https://doi.org/10.1016/ j.ultsonch.2014.05.027

Ismail, A., Hainida, E., Ikram, K., Saadiah, H. and Nazri, M. (2008). Roselle (Hibiscus sabdariffa L.) seeds nutritional composition, protein quality and health benefits. Food, 2(1), 1-16.

Lieu, N.L. and Le, V.V.M. (2010). Application of ultrasound in grape mash treatment in juice processing. Ultrasononics Sonochemistry, 17(1), 273 -279. https://doi.org/10.1016/j.ultsonch.2009.05.002

Mashkour, M., Maghsoudlou, Y. and Shahraki, M.H. (2013). Optimization of Roselle beverage formulation using response surface methodology. Quality Assurance and Safety of Crops and Foods, 5 (2), 119-129. https://doi.org/10.3920/QAS2012.0137

Mgaya, B., Remberg, S., Chove, B. and Wicklund, T.
(2014). Physio-chemical, mineral composition and antioxidant properties of Roselle (Hibiscus sabdariffa L.) extract blended with tropical fruit juices. African Journal of Food, Agriculture, Nutrition and Development, 14(3), 8963-8978.

Naimah, R., Nur Amirah, Y., Adzemi, M.A. and Wan Zaliha, W.S. (2014). Quality and growth development of roselle grown on bris soil in relation to regulated deficit irrigation. Journal of Tropical Plant Physiology, 6, 23 - 24.

Nath, A., Mukhim, K., Swer, T., Dutta, D., Verma, N., Deka, B.C. and Gangwar, B. (2014). A review on application of ozone in the food processing and packaging. Journal of Food Product Development and Packaging, 1, 7-21.

Nguyen, T.P. and Le, V.V.M. (2012). Application of ultrasound to pineapple mash treatment in juice processing. International Food Research Journal, 19 (2), 547-552.

Onopiuk, A., Półtorak, A., Moczkowska, M., Szpicer, A. and Wierzbicka, A. (2017). The impact of ozone on health-promoting, microbiological, and colour properties of Rubus ideaus raspberries. CyTA Journal of Food, 15(4), 563-573. https:// doi.org/10.1080/19476337.2017.1317669

Patil, S. and Bourke, P. (2012). Ozone processing of fluid foods. In Cullen, P.J., Tiwari, B.J. and Valdramidis, V.P. Novel Thermal and Non-Thermal Technologies for Fluid Foods, p. 225 - 261. Cambridge, Massachusetts: Academic Press. https:// doi.org/10.1016/B978-0-12-381470-8.00009-8

Patil, S., Torres, B., Tiwari, B.K., Wijngaard, H. H., Bourke, P., Cullen, P.J. and Valdramidis, V.P. (2010). Safety and quality assessment during the ozonation of cloudy apple juice. Journal of Food Science, 75(7), M437-443. https://doi.org/10.1111/ j.1750-3841.2010.01750.x

Phan, L.Z.N., Nguyen, T.N.T and Le, V.V.M. (2012). Ultrasonic treatment of mulberry (Morus alba) mash in the production of juice with high antioxidant level. Journal of Science and Technology, 50(3A), $204-$ 209.

Plotto, A., Baldwin, E.A., McCollum, T.G., Narciso, J.A. and Irey, M. (2008). Effect of early detection Huanglongbing on juice flavor and chemistry. Proceedings of the Florida State Horticultural Society, 121, 265-269.

Pozos, G.I.P., Ruiz-Lopez, M.A., Natera, J.F.Z., Moya, C.A., Ramirez, L.B., Silva, M.R., Macias, R.R., Garcia-Lopez, P.M., Cruz, R.G., Perez, E.S. and Radillo, J.J.V. (2020). Antioxidant capacity and antigenotoxic effect of Hibiscus sabdariffa L. 
extracts obtained with ultrasound-assisted extraction process. Applied Sciences, 10(2), 560 - 573. https:// doi.org/10.3390/app10020560

Prabha, V., Barma, R.D., Singh, R. and Madan, A. (2015). Ozone technology in food processing: A review. Trends in Biosciences, 8(16), 4031-4047.

Ramírez-Rodrigues, M.M., Plaza, M.L., Azeredo, A., Balaban, M.O. and Marshall, M.R. (2012). Phytochemical, sensory attributes and aroma stability of dense phase carbon dioxide processed beverage during storage. Food Chemistry, 134(3), $1425-1431$.

j.foodchem.2012.03.042

Santhirasegaram, V., Razali, Z., George, D.S. and Somasundram, C. (2015). Comparison of UV-C treatment and thermal pasteurization on quality of Chokanan mango (Mangifera indica L.) juice. Food and Bioproducts Processing, 94(August 2013), 313321. https://doi.org/10.1016/j.fbp.2014.03.011

Steenstrup, L.D. and Floros, J.D. (2004). Inactivation of E. coli $\mathrm{O} 157: \mathrm{H} 7$ in apple cider by ozone at various temperatures and concentrations. Journal of Food Processing and Preservation, 28(2), 103-116. https://doi.org/10.1111/j.1745-4549.2004.tb00814.x

Stein-Chisholm, R.E. (2015). Juice processing effects on small scale not from concentrate Rabbiteye blueberry juice production: the evaluation of juice recovery and identification of anthocyanins and anthocyanidins through processing steps. Louisiana: Louisiana State University, MSc Thesis.

Tiwari, B.K. (2015). Ultrasound: A Clean, Green Extraction Technology. Trends in Analytical Chemistry, 71, 100-109. https://doi.org/10.1016/ j.trac.2015.04.013

Tiwari, B.K., Muthukumarappan, K., O’Donnell, C.P. and Cullen, P.J. (2008). Modelling colour degradation of orange juice by ozone treatment using response surface methodology. Journal of Food Engineering, 88(4), 553-560. https:// doi.org/10.1016/j.jfoodeng.2008.03.021

Tiwari, B.K., O’Donnell, C.P., Patras, A., Brunton, N. and Cullen, P. J. (2009a). Effect of ozone processing on anthocyanins and ascorbic acid degradation of strawberry juice. Food Chemistry, 113(4), 11191126.

https://doi.org/10.1016/ j.foodchem.2008.08.085

Tiwari, B.K., O'Donnell, C.P., Patras, A., Brunton, N. and Cullen, P.J. (2009b). Anthocyanins and colour degradation in ozonated grape juice. Food and Chemical Toxicology, 47(11), 2824-2829. https:// doi.org/10.1016/j.fct.2009.09.001

Tiwari, B.K., O’Donnell, C.P., Muthukumarappan, K. and Cullen, P.J. (2009). Anthocyanin and colour degradation in ozone treated blackberry juice. Innovative Food Science and Emerging Technologies, 10(1), 70-75. https://doi.org/10.1016/ j.ifset.2008.08.002

Torres, B., Tiwari, B.K., Patras, A., Wijngaard, H.H., Brunton, N., Cullen, P.J. and O'Donnell, C.P. (2011). Effect of ozone processing on the colour, rheological properties and phenolic content of apple juice. Food Chemistry, 124(3), 721-726. https:// doi.org/10.1016/j.foodchem.2010.06.050

Vo, H.D. and Le, V.V.M. (2014). Optimization of ultrasonic treatment of rose myrtle mash in the extraction of juice with high antioxidant level. International Journal of Food Research, 21(6), 2331 -2335 .

Williams, R.C., Sumner, S.S. and Golden, D.A. (2004). Survival of Escherichia coli O157:H7 and Salmonella in apple cider and orange juice as affected by ozone and treatment temperature. Journal of Food Protection, 67(11), 2381-2386. https://doi.org/10.4315/0362-028X-67.11.2381

Wu, L.C., Hsu, H.W., Chen, Y.C., Chiu, C.C., Lin, Y.I. and Ho, J.A.A. (2006). Antioxidant and antiproliferative activities of red pitaya. Food Chemistry, 95(2), 319-327. https://doi.org/10.1016/ j.foodchem.2005.01.002

Youssef, M.A., El Kady, A.A. and Nagy, K.S. (2015). Effect of engineering treatments on extraction of Roselle juice (Karkdah). Middle East Journal of Agriculture, 4(4), 697-706.

Zaman, A.A.K., Shamsudin, R. and Adzahan, N.M. (2017). Storage effect on quality attributes of combine mild heat and ultraviolet irradiated Roselle (Hibiscus Sabdariffa) juice compare with thermal treatment. Presented at the International Conference on Food Science and Nutrition, 25 - 26 October 2017, p. 61-66. Kota Kinabalu, Sabah, Malaysia. 